Article

\title{
From the Museum to the Street: Garry Winogrand's Public Relations and the Actuality of Protest
}

\author{
Simon Constantine \\ Department of History of Art, University College London, London WC1E 6BT, UK; ucwcgsc@ucl.ac.uk
}

Received: 12 March 2019; Accepted: 16 April 2019; Published: 3 May 2019

\begin{abstract}
Focusing on Garry Winogrand's Public Relations (1977), this article explores the problematic encounter between street photography and protest during the Vietnam War era. In doing so, it considers the extent to which Winogrand's engagement with protest altered the formalist discourse that had surrounded his practice and the 'genre' of street photography more broadly since the 1950s. It is suggested that, although Winogrand never abandoned his debt to this framework, the logic of protest also intensified its internal contradictions, prompting a new attitude towards the crowd, art institution, street and mass media. By exploring this shift, this article seeks to demonstrate that, while the various leftist critiques of Winogrand's practice remain valid, Public Relations had certain affinities with the progressive artistic and political movements of the period.
\end{abstract}

Keywords: street photography; Winogrand; formalism; protest; Vietnam War; documentary

\section{Introduction}

In her 1981 essay, 'In, Around and Afterthoughts (on Documentary Photography)', Martha Rosler sought to reinvent documentary practice through a Marxist critique of its traditions, truth claims and political assumptions. However, in doing so, she also stressed the difference between this project and a second, reactionary attack upon photographic credibility; one conducted by a postwar art establishment, which sought to secure 'the primacy of authorship' and avoid the social by isolating images 'within the gallery-museum-art-market nexus' (Rosler 1992, p. 320). Her clearest targets were the photographers championed by MoMA's director of photography, John Szarkowski, in the 1967 exhibition New Documents: Diane Arbus, Lee Friedlander and Garry Winogrand. In Rosler's view, these street and antihumanist photographers had rescinded all responsibility towards their subjects, abandoning what remained of the pre-war social documentary tradition and indulging in a virtuoso celebration of photographic form. Consequently, they were not only complicit with Szarkowski's modernist-formalist curatorial strategy but epitomised his attempt to locate a new mode of documentary practice which, to paraphrase the exhibition's infamous wall text, made no claim to reform or understand the world, but simply 'enjoyed life despite its terrors' (Szarkowski 2017, p. 1). Such a framework, Rosler concluded, was particularly irresponsible at a moment in which America was already several years into the 'terrors' of the Vietnam War. Consequently, those who sought to reinvent documentary practice had clear adversaries in New York's most powerful art institution.

This demarcation of late 1960s and 1970s photography into left- and right-wing camps is well known today and remains broadly useful. However, this essay will seek to explore a complicating factor: the disproportionate quantity of 'protest images' produced by photographers which Rosler associated with the (formalist) right. Indeed, whilst leftist photographers of this period were certainly in protest, 
it is difficult to find a significant document of protest in their work. ${ }^{1}$ Of all the figures associated with Rosler and the San Diego group, only Fred Lonidier explicitly photographed a demonstration. ${ }^{2}$ This is also broadly true of conceptual and neo-avant-gardist photography, even if groups, such as the Art Workers Coalition, used photographs in protests and were photographed protesting. In contrast, the street photographers associated with MoMA had been depicting demonstrations since the 1950s, as can be seen in Lee Friedlander's and Danny Lyon's images of the civil rights movement. Garry Winogrand, the subject of this article, also made many images of the demonstrations and sit-ins of the Vietnam War era. Of course, I am not suggesting that this fact alone invalidates the critique of such photographers; the mere depiction of protest is not progressive in and of itself. Furthermore, the left's tendency to sidestep this subject matter had several causes, including its critique of photographic humanism, iconic images and the mere 'representation of politics'. ${ }^{3}$ Nevertheless, several questions remain unanswered: how might we define the encounter between street photography and protest? Did this engagement rupture its institutional framework? Was it in any way influenced by the strategies of the political and photographic left?

This article will address these questions through an analysis of Garry Winogrand's Public Relations, a MoMA exhibition and photobook arranged by Tod Papageorge in 1977. Shot largely between 1969 and 1973, the project was a notable departure from the skewed, largely apolitical shots of pedestrians, partygoers and zoo animals, which had secured Winogrand's status as the archetypal formalist street photographer. Indeed, at least 19 of the 76 photographs that appeared in the exhibition were taken at demonstrations, and many others depicted political subjects-including the 1971 presidential candidates' press conference, New York's mayor John Lindsay and the Nixon victory celebration of 1972. However, the problematic status of these images soon becomes apparent. Winogrand's project stemmed from a 1969 Guggenheim fellowship concerning 'the effect of media on events'. ${ }^{4}$ Consequently, it subsumed the theme of protest into a broader investigation of the public event by including shots of sporting events, art openings and the Apollo 11 launch. With no explanatory text from the photographer and only the sparsest of captions, the project made little attempt to contextualise these phenomena. Instead, according to Papageorge's wall label, it indiscriminately poked fun at them as forms of 'erzatz ritual' staged for the mass media (Watson 2016, p. 5). Of course, this was not the only interpretation suggested by Winogrand's defenders. In his introduction to the 1988 retrospective Figments from the Real World, Szarkowski argued that, while easily distracted by the tangential, Winogrand made a genuine attempt to document America's public behaviour during this period (Szarkowski 1988). Others, such as Leo Rubinfien, claimed that Public Relations evinced a certain sympathy with the protestors, albeit one tempered by a generation gap (Rubinfien 2013, p. 39). Yet, despite their differences, each of these interpretations tended towards the same conclusion: Winogrand was more interested in the photographic problems posed by his subject matter than its social content. In this sense, the discourse of media cynicism and thematic digression that surrounded the work sought to elevate it from the political to the level of pure form.

Given this discourse, it would be deeply problematic to simply 'recuperate' Winogrand's work for progressive ends. Nevertheless, in their rush to insulate the project against political readings,

1 Key exceptions to this general tendency can be found within the field of photojournalism. However, during the 1970s and 1980s Rosler and her peers tended to treat this practice as a form of photographic liberalism, partly due to the dominance of 'concerned photography': a form of humanist photojournalism with links to the Democratic Party. For a useful account of the political divisions within American photography during the 1970s see (Ribalta 2015).

2 I allude to Londier's 29 Arrests (1972), a work which parodied Ed Ruscha's Twentysix Gasoline Stations (1963) by displaying 29 images of protesters arrested at a demonstration outside the Headquarters of the 11th Naval District in San Diego in a pseudo-conceptualist grid.

3 As Julia Bryan-Wilson argues, a tendency to address the war and peace movement through indirect means, or refuse to depict them entirely, was a common feature of engaged practices during this moment. See (Bryan-Wilson 2009, p. 9).

4 According to Leo Rubinfien, Winogrand's original Guggenheim application did not, in fact, contain the phrase 'the effect of media on events'. Rather, he likely mentioned it to Papageorge during the making of the exhibition. (Rubinfien 2013, p. 58, n. 96). 
Winogrand's formalist supporters also hinted at the potential threat which protest posed to their understanding of his practice. Could Public Relations exemplify another claim made by Rosler: that the 'force [of documentary practice] derives at least in part from the fact that the images might be more decisively unsettling than the arguments enveloping them' (Rosler 1992, p. 306). Of course, it would not be possible to simply separate the photographs from their discourse situation to reveal what Gerry Badger once called the "'good Winogrand" [ ... ] permeated with a social sense' (Badger 1988, para. 14 of 26). While a more extensive, or less problematic, depiction of protest could doubtless be found in the images which were excluded from the exhibition and book, Winogrand was such a prolific photographer that this approach could be used to support any number of claims. Furthermore, there is no good reason to assume that Papageorge, or the other formalist critics, fundamentally misrepresented the photographer's intentions. Winogrand was closely associated with all of them and, on the few occasions in which he was forced to comment on the project's politics, tended to echo their interpretations (or propose even more discomforting ones). ${ }^{5}$ However, while Public Relations emerged from a formalist problematic, it did not simply leave it unchanged. Indeed, it will be my contention that, when brought into contact with protest, Winogrand's street photography experienced a type of internal mutation or dialectical reversal. To address 1960s and 1970s protest culture, was to approach the formalist concept of street photography from within an alien register; one that risked overturning it from within and placing it on a new path.

\section{Protest in Photography}

"The critic Ian Jeffrey once asked rhetorically why Winogrand was so important. Part-a vital part-of the answer is that like André Kertész, Henri Cartier-Bresson and Robert Frank before him, Winogrand was a street photographer. That genre-freewheeling, casual, intuitive, essentially experimental-brings us, it seems to me, close to the existential heart of the photographic process. It demonstrates in its purest form the far from simple impulse to observe, reach out, and encapsulate a fragment of actuality [ ... ]. The broadly diaristic nature of this process, exemplified in the sixties and by Winogrand in particular, results not in reports but in confessions. And (never far away from confessions) in playing games". (Badger 1988, p. 24)

The above statement is as good a place as any to start unpacking the notion of street photography represented by Winogrand and the internal threat posed to it by protest. In fact, while Gerry Badger's article gestured towards a social reading of Winogrand's practice, this comment on the photographer's importance is underpinned by a formalist understanding of street photography as the most medium-specific photographic 'genre'. Badger does not simply grant the genre this status because of its adherence to the established principles of straight photography. He also suggests that the fragmentary, diaristic form of observation demanded by working in the street reveals the medium's 'existential heart' by purging it of reportage. In this sense, it would seem that street photography-a type of 'art documentary' which privileges experimental, personal, elliptical or even comic results - radically differs from protest photography, however one chooses to define it. Indeed, throughout its many manifestations, protest photography has tended to favour the exact opposite strategies, from instrumental realism to the refusal of authorship and outright political agitation. The early twentieth-century worker photography movement, for example, commonly viewed experimentation as a concession to 'bourgeois aesthetics' and implored the photographer to act as part of a collective. However, as Badger suggests, street photography acquired its classic formalist

5 During the making of Public Relations, Winogrand tended to short-circuit political readings of his work by suggesting that he was only interested in the photographic problems posed by his subject matter. However, towards the end of his life, he often adopted a dismissive or openly hostile attitude towards the protestors. For a telling example of this see (Diamonstein and Winogrand 1982). 
guise during a moment, the sixties, in which protest was never far from its privileged terrain. Indeed, Public Relations shows us what happens when protest, both literally and metaphorically, occupies the pure space of the street photograph. Before addressing how this encounter affected Winogrand's practice, it is therefore necessary to consider how the discourse of street photography sought to control it and the compromises which this required.

The main interpretive framework which surrounds Public Relations is that of Tod Papageorge, the photographer, curator and writer who designed the exhibition, sequenced the book and wrote the catalogue essay. Having selected the 76 photographs which appeared in the show from over 6500 proof prints, Papageorge bears a significant responsibility for the major document of protest which appears in the project. ${ }^{6}$ Furthermore, as the installation shots show, he granted images of social activism pride of place, presenting them in dense groups of seven or eight which recurred throughout the hang. This active prioritisation of protest continues in the introduction to the book which, despite its near-monographic range and frequent formalist motifs, contains one of the most extensive commentaries on the project's content to emerge during the photographer's lifetime. However, it is in this commentary that Papageorge's conflicted relationship towards the protest image begins to surface. For example, in a telling and oft-quoted passage we are told that the photographs provide 'evidence [ ... ] of the collective hysteria which locked us into "the sixties"' and 'how we behaved under pressure during a time of costumes and causes, and of how extravagantly, outrageously, and continuously we displayed what we wanted' (Papageorge 1977, pp. 14-15). In making these comments, Papageorge went further than Badger by evoking the connection between Winogrand's photographs and the explicit politics of 'the sixties'. However, he did so only to reassure the reader that they depicted a moment which had, at long last, ceased to have any bearing upon the present. While this framing was partly inevitable given the retrospective sequencing of the project, Papageorge's evocation of public extravagance, and even hysteria, suggests that the unease provoked by Winogrand's image of 'the sixties' and its immediate aftermath had deeper causes.

To appreciate the structural basis of this discomfort it is useful to explore the contrast between Winogrand's images of Central Park demonstrations and the photographs which Papageorge produced whilst walking through the park to curate the exhibition in 1977. Recently published as Passing through Eden, these shots did not so much respond to Public Relations as attempt to purify its subject matter by reviving an idealised version of classical street photography (Papageorge 2008). In stark contrast to the chaotic and crowded shots of Winogrand's work, Papageorge depicted the park as a tranquil, near-bucolic tabula rasa. No large crowds appear in this 'Edenic' space. Rather, we see individuals, couples or small groups engaging in conversations, kissing, sleeping, sunbathing, eating or reading, all glimpsed in passing by a photographer in motion. Consequently, the public behaviour of the figures seen in Winogrand's images is replaced by a sense of relative privacy punctuated by moments of ambiguous interpersonal drama. While this view of Central Park partly reflected the declining militancy of the late 1970s, it also pinpointed one of the features which made protest so intolerable to street photography: its rejection of the bourgeois division between public life and private experience. Indeed, Papageorge inadvertently demonstrated that street photography treated this division as its 'blank canvas', hunting for (or provoking) situations in which private experience briefly and ambiguously erupted into public life. Protest, on the other hand, involved the active reclamation of public space through the collective expression of ideas and emotions. Impersonal, sustained and as unambiguous as possible, it intentionally removed the basic hinge which had been crucial to the street photograph's mystery. In this sense, Winogrand's protest images risked returning to reportage, not because they were straight photographs, but because the protestors drowned out the 'confessions' and 'fictions' of the street photographer with banners and demands.

6 According to Szarkowski, Winogrand also played a partial role in this selection process, offering 'some guidance and the very rare exercise of authority' (Szarkowski 1988, p. 32). 
As a result, Papageorge's introduction and image selection for Public Relations attempted to nullify this politicised public behaviour by constructing a series of dubious equivalences. Most obviously, it sought to impart a sense of self-serving promotion to the act of protest by conflating it with other events arranged for the mass media. The suggestion that each of the figures depicted in the photographs—-be they sports stars, politicians, art-world doyens or protestors-'outrageously [ ... ] displayed what [they] wanted' implied that they all had the same base motivation for being in the public eye: to have their 15 minutes of fame (Papageorge 1977, p. 15). Indeed, the sequence even contains a picture of Andy Warhol at a Frank Stella opening! However, given that the book project also included shots of the so-called hard-hat protests, which were organised by pro-war construction unions to disrupt the antiwar movement, Papageorge's comments on 'collective hysteria' suggested an even more problematic equivalence. In the Public Relations hang, the most famous of these hard-hat images, New York City, was placed next to shots of police brutality, peace marches and sit-ins, implying an identity between opposing groups (Figure 1). A sense of millenarian fanaticism was also imparted to the block of photographs through the inclusion of an image showing protestors marching under a dense array of flags and crucifixes (Figure 2). In each of these ways, the exhibition sought to construct an image of an America which had temporarily lost its reason-engaging in forms of collective behaviour, or even therapy, that were equally irrational, be they left or right. While this picture pilloried the Nixon regime as much as it did the protestors, it was, at best, a liberal critique of the Vietnam War era as collective folly - at worst, a photographic visualisation of the so-called horseshoe theory.

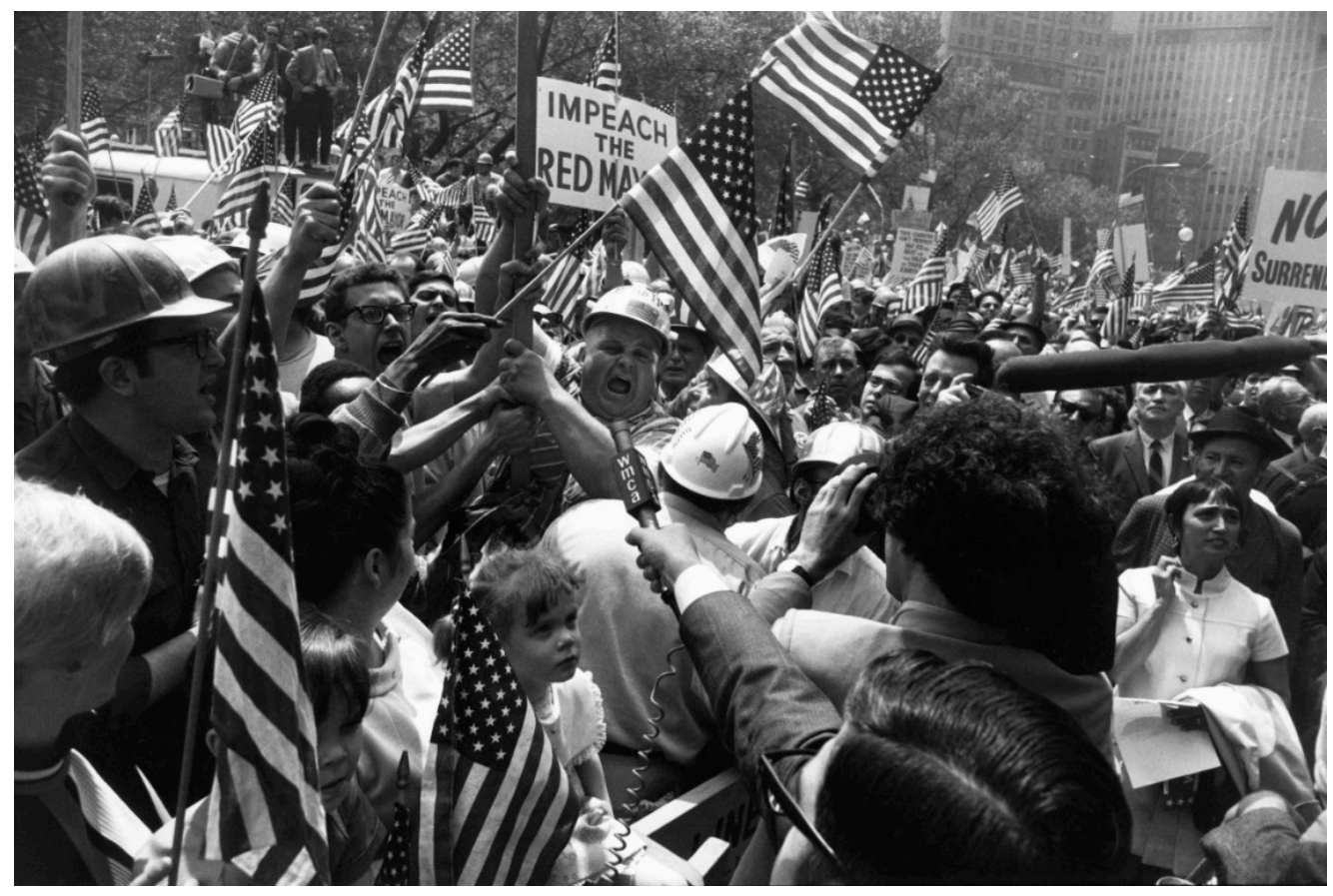

Figure 1. Garry Winogrand, New York City, 1969, Gelatin silver print, $27 \times 40.4 \mathrm{~cm}$, Museum of Modern Art, New York, USA. (C) The Estate of Garry Winogrand, courtesy Fraenkel Gallery, San Francisco.

At the moment of their production, however, the photographs were enveloped in a different, if equally problematic, discourse: that of John Szarkowski. It is often assumed that Szarkowski's exhibition programme during the 60 s and 70 s avoided addressing the Vietnam War. And, indeed, this is largely true of the main shows featuring work by Winogrand at this time-namely, New Documents and The Animals. ${ }^{7}$ However, during this period, Szarkowski did combine images from Public Relations

7 For an alternative reading of The Animals, as a satire of American society during the Vietnam War, see (Balaschak 2012). 
with others by photojournalists, including Benedict J. Fernandez and several Magnum photographers, to curate a lesser-known exhibition entitled Protest Photographs. Opening at MoMA on 23 May 1970, the timing of this show was anything but coincidental. Less than a month before, President Nixon had announced the Cambodia campaign, giving rise to a wave of protests which culminated in the Kent State shootings on 4 May. As Christopher Phillips notes, the show appeared to recognise these events by presenting the shots unmounted as if 'hot off the press' (Phillips 1982, p. 60). Indeed, correspondence preserved in the MoMA archive shows that, while the Winogrand works were already in the collection, Szarkowski had the Fernandez negatives hastily shipped in and printed in an apparent attempt to fill gaps in the show's coverage (Szarkowski 1970). The exhibition hang also hinted at a form of photo-essayistic narrative by building up to a single, soon to become iconic, image: John Filo's shot of Mary Vecchio kneeling over the fatally wounded student Jeffrey Miller at Kent State. ${ }^{8}$ However, in a gesture which would later be repeated in Public Relations, the show was otherwise lacking in contextual information, beyond the locations of the photographs and the names of the photographers. Furthermore, Szarkowski insisted that the photographs be printed at $16 \times 20$ inches with a one-inch border, a format which had strong associations with his exhibitions of art photography. In this sense, the show granted press images an unusual parity with those of Winogrand, adopting an ambiguous position between art and photojournalism.

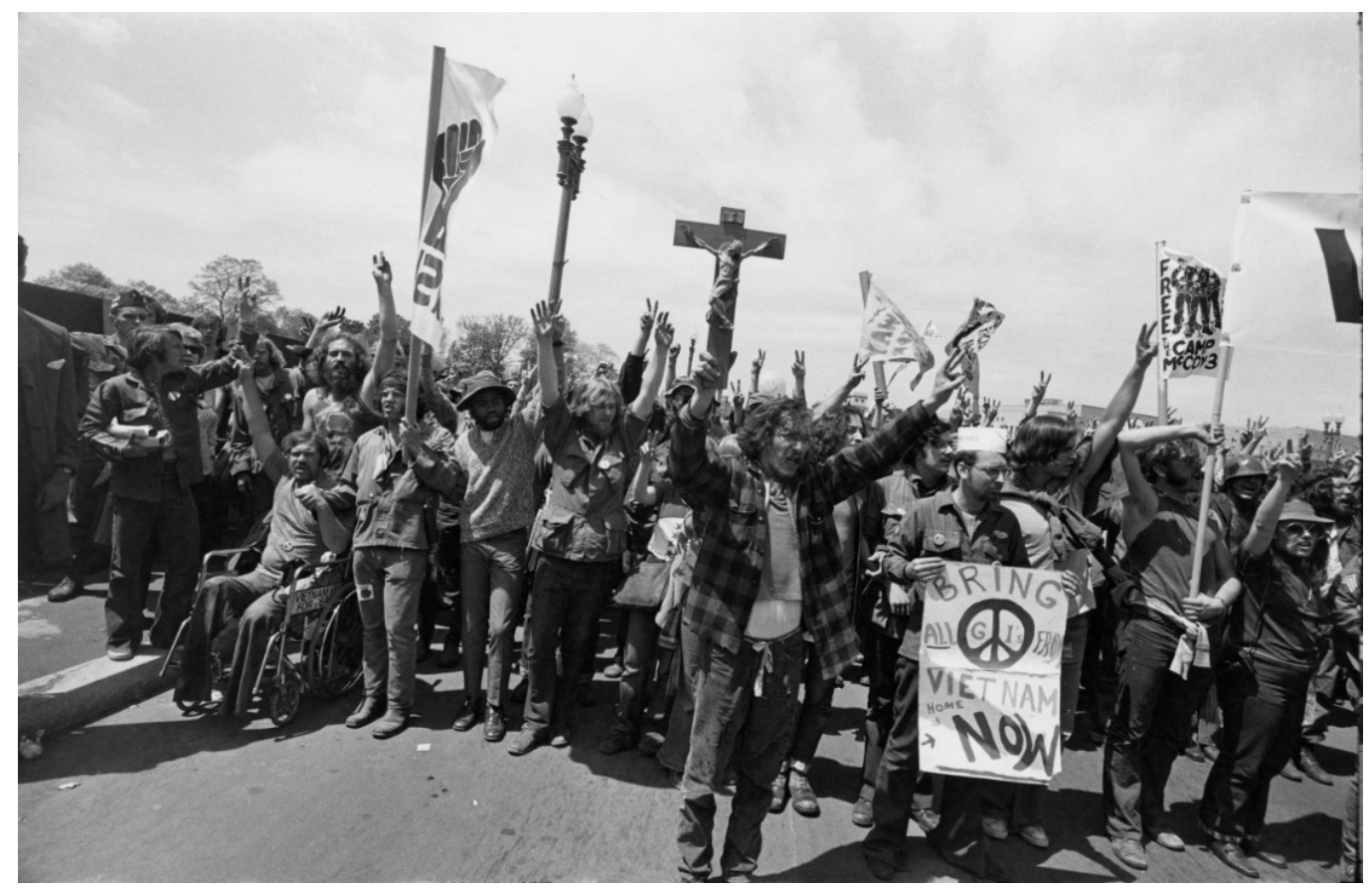

Figure 2. Garry Winogrand, Peace Demonstration, Washington, DC, 1971, Gelatin silver print, $26.4 \times 40.4 \mathrm{~cm}$, Museum of Modern Art, New York, USA. (C) The Estate of Garry Winogrand, courtesy Fraenkel Gallery, San Francisco.

Consequently, while Protest Photographs may have been an attempt to answer criticism of the museum's political quietism, it was also something of a precursor to one of Szarkowski's most overtly formalist experiments: the 1973 exhibition From the Picture Press. By displaying press images without their captions, this exhibition adopted a near-Greenbergian approach to medium specificity. Yet whereas Greenberg understood photography as a content-based medium, Szarkowski sought to secure its formal autonomy by demonstrating that even the most apparently informative photographs could only convey

8 For an account of the iconic status of this photograph see (Lucaites and Hariman 2007). 
a simple, fragmentary message (Greenberg 1986). The images, which had been partly researched and selected by the late Diane Arbus, were gathered under generic titles intended to illustrate this narrative simplicity, such as 'Disasters', 'Winners' and 'Losers'. These titles could have easily included 'Protest'. Indeed, it is possible to assume that Szarkowski viewed the images featured in Protest Photographs in a similar light to those of the 1973 exhibition: as mere 'symbols' which failed to explain the full meaning of the events in question (Szarkowski 1966, p. 8). In this sense, Protest Photographs encouraged the viewer to treat images of social activism like street photographs, focusing upon incidental details or moments of formal coherence, rather than their supposedly unrepresentable political content. While this framing may have been appropriate for Winogrand-at least in Szarkowski's view_it was hardly representative of the other photographs in the exhibition. ${ }^{9}$ For example, as John Lucaites and Robert Hariman demonstrate, John Filo's image had already been widely disseminated in protest flyers and literature with the intention of organising further demonstrations against the war and police violence (Lucaites and Hariman 2007, pp. 152-54). Consequently, conflating this type of imagery with photographs by Winogrand served to downplay the galvanising effect which it was having upon the peace movement. In short, for Szarkowski, the images later included in Public Relations were literally protest 'in' photography; social activism safely contained within the 'four walls' of the photograph and the art institution.

\section{The Museum and the Street}

The institutional frameworks which surrounded Winogrand's project, both during and after its production, demonstrate why the formalist understanding of street photography was either incompatible with protest or served to reduce it to business as usual. Nevertheless, by studying the differences between Szarkowski's and Papageorge's framings of the project, it is also possible to see how certain aspects of Winogrand's work either troubled photographic formalism or pushed it in unlikely directions. The years 1970-1977 played host to a series of historical developments which significantly altered the reception of Winogrand's work. Most obviously, in 1974 Nixon resigned following the Watergate scandal, paving the way for the end of the Vietnam War in 1975. By 1977, the photographic medium also enjoyed a significantly more established position within the art institution and market; a meteoric rise subsequently referred to as the 'photo-boom'. ${ }^{10}$ Consequently, while Papageorge's curatorial approach downplayed the political implications of Winogrand's photographs, it also unveiled certain aspects of the project which would have been intolerable in 1970_at the height of peace movement, when photography was still partly external to the art establishment. In what follows, I will seek to demonstrate how, at these points of rupture, Winogrand pushed classical street photography into an uneasy parallelism with protest.

To appreciate the subversive potential of Winogrand's project it is important to address, not only his shots of protests, but also his images of exhibition openings. Towards the end of Winogrand's life, these photographs were read either as quaint archival records or as loving send-ups of the rich and powerful, akin to his earlier photographs of party goers and businessmen. ${ }^{11}$ It was this kind of imagery which led the photography critic A.D. Coleman to argue that Winogrand's 'professional and economic allegiance is to the upper class [and] the museum/gallery network' (Szarkowski 1988, p. 33). Nevertheless, it is telling that at the historical moment in which Winogrand was taking the photographs Szarkowski was willing to display the protest images, but studiously avoided his shots of

9 Szarkowski's later suggestion that Winogrand went to photograph one theme-the effect of media on events-but became distracted by 'minor contingencies' suggested that he was instinctively aware of the medium's representational limitations (Szarkowski 1988, p. 32).

10 In the year in which Public Relations was staged, Christies' and Sotheby's New York opened photography departments and the city played host to at least 10 photography auctions. See (Hacking 2018, p. 186).

11 For example, as Pepe Karmel wrote in 1981, 'Winogrand basically has an indulgent, even admiring attitude toward the rich, powerful, and renowned: he seems to feel at heart that they are awfully lucky to be able to make such fools of themselves, without worrying about the consequences' (Karmel 1981, p. 41). 
the artworld elite. One possible reason for this is that since the late 60s MoMA had itself become the target of protest on account of its muted response to the war and board of trustees, which infamously included Nelson Rockefeller: the Republican governor of New York and a key supporter of the war effort. During the early 1970s, groups such as the Art Workers Coalition produced a series of works which revealed the corporate connections of this and other boards. Indeed, just a day before the opening of Szarkowski's Protest Photographs, these actions culminated in the famous Art Strike against Racism, War and Oppression, which demanded that all museums close for the day.

Of course, this is not to suggest that Winogrand challenged or analysed the artworld to the same extent as these groups. Although he depicted Rockefeller and others, no figures were named in the accompanying captions. Nevertheless, his images do suggest an attempt to bring this institutional framework into the public eye. The only photographer in the room, Winogrand appears as a kind of counterspy within the New York Glitterati; someone invited to the exclusive events yet partly distant from them. As such, we are presented with a detached study of people chatting, flirting, eating and, most importantly, shaking hands. Winogrand was known for capturing these gestures, and the ambiguous stories which they implied, in the streets of Manhattan. In this context, however, this aspect of street photography was transformed into an unambiguous comment on social and economic capital. By 1981 Winogrand was quite explicit about the political-economic purpose of such events, stating that 'In the case of museums, it's always got to do with money, people who donate and things like that [... ] But there's nothing evil about it' (Diamonstein and Winogrand 1982, para. 29 of 215). This remark, like most of the comments on politics which appear in Winogrand's interviews, is imbued with a laconic cynicism. Yet even if the photographs had been similarly blunt, they were clearly understood as a threat to the museum at their moment of production; more shocking than openly political images which allowed the institutional framework to remain invisible.

By showing art being consumed, traded, displayed and funded for private gain, these images also call into question the pictorial self-sufficiency which Szarkowski attributed to the protest images. Indeed, Winogrand's approach to the paintings at these events even suggests a disdain for the finished art object. For example, his images of a 1970 Frank Stella opening at MoMA make heavy use of flash, picking out the figures in the foreground, yet consigning the paintings to darkness. In fact, it is characteristic of these shots that the depicted figures seem to be more interested in one another than the artworks, which are reduced to an incidental background. Winogrand had a similar attitude towards his own images, even if he benefitted from their display at MoMA. Indeed, as Public Relations demonstrates, he tended to separate his practice from its printing, editing, arrangement, interpretation and exhibition; tasks which he largely delegated to others. Many of Winogrand's champions sought to defend this practice by treating it as a byproduct of his 'restless genius'. But, in reality, it caused them significant discomfort. The problem was not just that he left his work undeveloped or allowed it to get damaged, but that he made huge amounts of it, leaving editors such as Papageorge to pick out the 'masterpieces'. These aspects of his practice became more pronounced during the making of Public Relations and especially toward the end of his life, where they were treated as evidence of his artistic decline. For example, when confronted with the 9000 rolls of film which Winogrand left undeveloped or unproofed at his death in 1984, Szarkowski commented forlornly that 'To expose film is not quite to photograph' (Szarkowski 1988, p. 36).

Yet Winogrand's increasingly-prolific approach to photography could also be understood as a process-based turn within his oeuvre. By the 1970s, Winogrand's tendency to 'overshoot' could no longer be treated simply as evidence of his indifference to content or enraptured immersion. Rather, it implied a submission of control and selfhood to the near-automatic activity of taking pictures. As Lucy Soutter notes, through this process, Winogrand increasingly dispensed with the most-basic rudiments of composing a shot, resulting in photographs which are 'interesting to look at specifically because they teeter on the brink of banality' - a kind of aesthetic deskilling not dissimilar to that employed by certain conceptual photographers (Soutter 1999, p. 9). However, these photographs shared another feature with the conceptual use of photography, in that they were more 
important as records of movement than as finished art objects. Indeed, when asked why he made art, Winogrand would simply say 'It's a way of living. It's a way of passing through the time' -as if attempting to minimise the difference between the practice of photographing and everyday life itself (Szarkowski 1988, p. 32). Consequently, while Winogrand has often been treated as a single-image photographer, the shots contained in Public Relations must be seen in the opposite way: as cross-sections of a near endless stream, limited only by Winogrand's own movement. Working in this way allowed him to deny the hierarchal divisions between different aspects of life. Indeed, there are many stories of Winogrand dashing into MoMA fresh from the street with little respect for their difference. Winogrand may not have challenged the privileges which allowed him to traverse these boundaries so fluidly. However, in crossing them, he not only brought the artworld closer to the street; he also brought the street, and its crowds of protestors, closer to art.

Winogrand's increasingly processual practice even led him to a certain understanding of protest as an artistic activity in its own right. The clearest evidence of this is his interest in the hand gestures, banners, placards and other objects used by the protestors, as seen in an image such as Peace Demonstration, Washington, D.C. (Figure 2). However, whilst he clearly appreciated the incongruous juxtapositions and theatricality of these displays, he did not treat them-as Szarkowski presupposed-as merely one means amongst others for creating finished, if unorthodox, pictures. Rather, Winogrand attempted to keep both the placards and the photographs in motion. The placards are usually at the head of a moving crowd, shot using his trademark tilted frame and wide-angle lens to increase the dynamism. The resulting shots are infused with a type of kinetic force. They attempt to transcend their status as still images by sustaining the kind of energy which he also sought in his own practice. But did Winogrand integrate his processual practice into the political activity of such groups? According Joel Meyerowitz, all the major street photographers including Winogrand 'went to every public demonstration, every "be in" in the park, all the gatherings down in the Forties and Times Square; wherever there were marches, we all went. [ . . . ] You lent your body to them because it was right' (Westerbeck and Meyerowitz 2001, p. 375). But is this strictly true? What was Winogrand's relationship towards these new, politicised articulations of the crowd? Did his way of photographing, as a way of moving through life, extend to participating in demonstrations and capturing them from the inside?

To answer these questions, we must briefly consider how Winogrand approached the crowd in his earlier work. Despite the popularity of this field, its social framework is rarely examined. For example, it is common to read that Winogrand addressed the 'democratic' crowd or that street photography was his 'republic', but what exactly does this mean? ${ }^{12}$ In his essay 'Commons and Crowds', Steve Edwards argues that street photography was based upon a 'paradoxically detached immersion' (Edwards 2009, p. 453). Underpinning this was an understanding of the crowd as a 'flow of endless particularity' reducible to its constituent parts (Edwards 2009, p. 453). Consequently, the street photographer both sought to isolate anonymous individuals within the crowd and assumed their own 'unique subjectivity as a figure outside of the mass' (Edwards 2009, p. 453). I would add that this sense of mutual separation was also underpinned by a notion of photographic citizenship, albeit not the transactional one recently proposed by Ariella Azoulay, but another based on a notion of negative rights. To be more specific, street photography presupposed that the medium itself granted its subjects a certain right to privacy and freedom, on account of its fleeting nature and incapacity to go beyond the visual. This formalist assumption was closely guarded as it served to justify the aggressive approach exemplified by much of Winogrand's earlier work. For example, as Tod Papageorge claimed in his introduction to Public Relations, the argument that the photographer has a 'moral' responsibility towards their subject is, in fact, an 'old confusion' because even the most intrusive photograph is 'just a picture' and has no

12 For example, as Ben Lifson put it, 'Winogrand's cast of characters is equally American-that is, motley, democratic. His crowded pictures are like visual town meetings, open to everyone, with no previously assigned seats [ ... ]' (Lifson 1982, p. 33). 
immediate connection with those who it depicts (Papageorge 1977, p. 15). This understanding of photography — as a kind of automatic barrier between the photographer and the depicted subject-has frequently been criticised for occluding a series of power relations. However, protest presented it with another challenge: an attempt to reach across the supposed barrier to form consensual relations of solidarity. In this sense, while the street photographer happily inhabited the average, alienated street crowd, they tended to see collective action-however peaceful—as an attack upon the photographer's autonomy. In short, for all its talk of democracy, street photography feared the 'tyranny of the majority'.

\section{4. 'Sly' Photojournalism}

Returning to Public Relations, it seems clear that this cautious relationship towards the politicised crowd remains at least partially present. If Winogrand 'lent his body to the crowd', as Meyerowitz claims, the evidence is rarely there in the pictures, which are largely shot from the sidelines or facing into an advancing march (Figure 2). Yet while he may not have been willing to become a participant observer, photographing demonstrations forced Winogrand to realise that his movement was not simply that of the autonomous street photographer. Rather, to follow a demonstration from the sidelines was to join the group of photojournalists who gathered to photograph the event. In a 1981 interview with Barbaralee Diamonstein, Winogrand even suggested that he was more interested in the challenges posed by adopting this position than in the project's official theme:

Winogrand: I went to events, and it would have been very easy to just illustrate that idea about the relationships between the press and the event, you know. But I felt that from my end, I should deal with the thing itself, which is the event. I pretty much functioned like the media itself.

Diamonstein: But weren't you the media then?

W: I was one of them, yeah, absolutely. But maybe I was a little slyer, sometimes.

(Diamonstein and Winogrand 1982, p. 215)

Winogrand had been 'one of them' before, having initially supported his street photography through a career in photojournalism and advertising, a job which he had only abandoned in 1969 to pursue a role in teaching. However, his comment on being a 'little slyer' suggests an attempt to pursue press photography within a different, perhaps more critical or satirical, register. What exactly did he mean by this? Did it allow him to overcome the longstanding problems which have tended to arise from the encounter between protest and the mainstream media?

Before answering this second question, it is necessary to consider what Winogrand's 'sly' photojournalism looked like in practice and explore its political implications. The photographs in Public Relations come in two basic forms: first, shots of events designed, at least in part, to be captured and publicised through photography and, secondly, images which capture the participants, the journalists and their recording equipment, demonstrating how the press channelled the event into a series of photo-ops, interviews and other spectacles. In this sense, Winogrand simultaneously behaved like the media and took a sideswipe at it, criticising its effect upon public life. This assessment of mass-mediatised 'reality' had longstanding precedents on the left. For example, in 1927 the Marxist critic Siegfried Kracauer had complained that, with the rise of the American illustrated magazine, 'the world itself has taken on a "photographic face": it can be photographed because it strives to be absorbed into the spatial continuum which yields to snapshots' (Kracauer 1995, p. 59). This led him to conclude that photography was the 'go-for-broke game of history', in that-despite weakening our associative faculties - it had the revolutionary potential to reveal the provisional status of any given reality. However, for Papageorge Winogrand's images evoked a significantly less dialectical theoretical framework: the conservative historian Daniel J. Boorstin's notion of the 'pseudo-event' (Watson 2016, p. 5). Boorstin had coined this term in his 1962 book The Image to describe the rise of 
planned events which had little purpose other than to garner news coverage (Boorstin 1962, pp. 11-12). ${ }^{13}$ However, while Boorstin's argument was superficially similar to leftist critiques of media spectacle, it concluded with a patriotic call to resist the semireligious attraction of illusions and restore the rugged individualism of American life. In their measured ambiguity Winogrand's photographs could sustain both political interpretations, seemingly typifying his tendency to 'sit on the fence'.

Nevertheless, if we return to the protest images, is it possible to detect a specific stance? To my mind, these images are by no means free of a certain distaste for the planned protest which manifests in a search for forms of 'authenticity'. For example, Winogrand frequently attempted to capture the nervous atmosphere, or sense of confusion, which accompanied an outwardly hopeful demonstration (Figure 3). His tendency to privilege marches over static forms of peaceful protest such as rallies also implied a preference for spontaneity and action. However, Winogrand was not naïve about the need for political movements to strategically mobilise press coverage and, in this sense, his critique of inflated media artifice was more relevant to the other events depicted in the book (Diamonstein and Winogrand 1982, para. 19 of 215). Indeed, excepting his images of protestors being interviewed, Winogrand saved his most acerbic deconstructions of the staged event-in which wires, lights and recording equipment are visible-for his shots of patriotic marches, official politics or actual media events. The protest images, on the other hand, both tackled the event head on and treated it as a space for photographic experimentation. Despite making formalist claims for his originality, this hybrid of street photography and photojournalism also stopped him from reproducing the negative attitude towards protest which dominated mainstream coverage of the antiwar movement. In what follows, I will seek to demonstrate this by discussing two examples: his depictions of 'violence' and the politicised crowd.

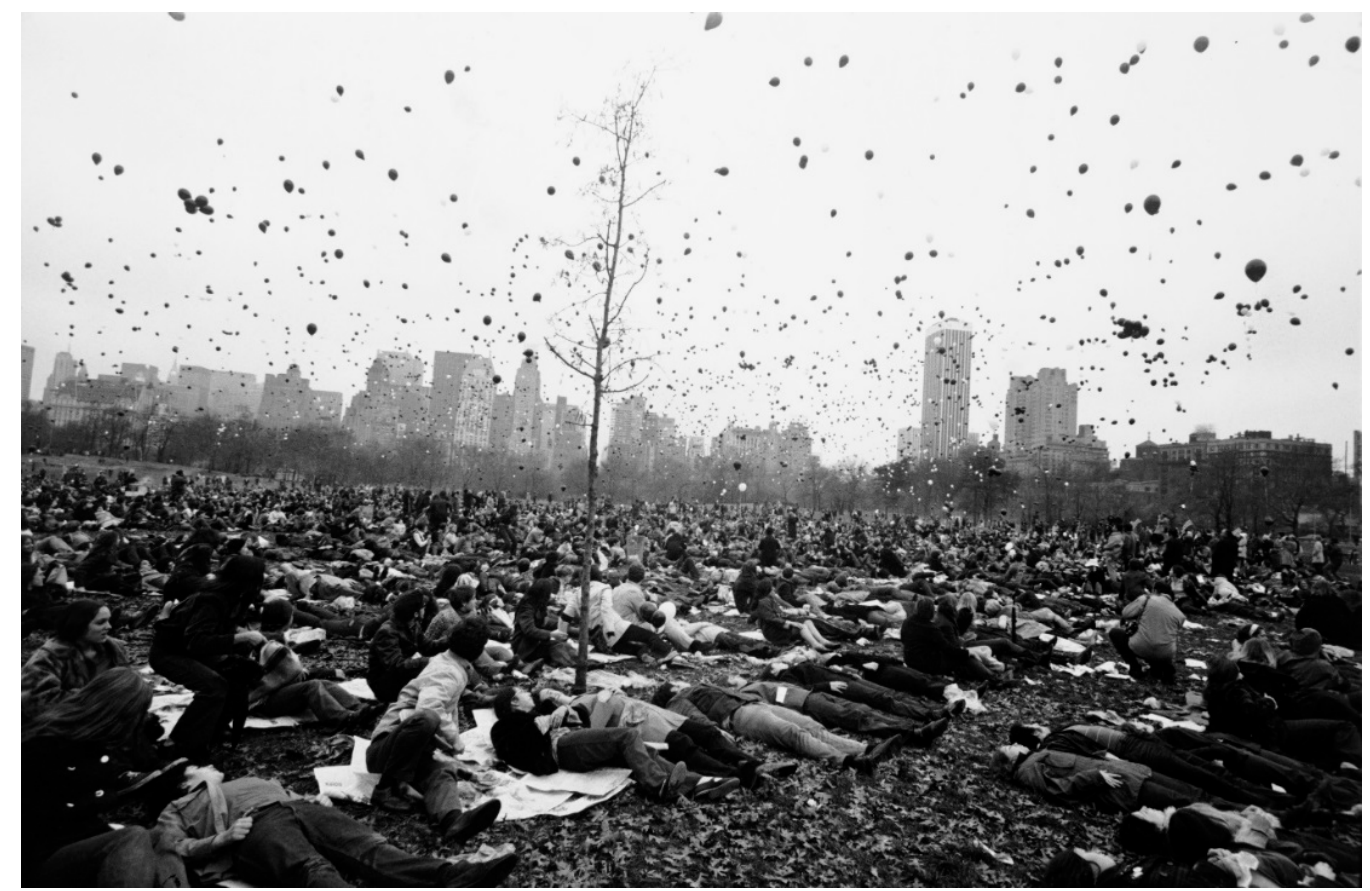

Figure 3. Garry Winogrand, Peace Demonstration, Central Park, New York, 1970, Gelatin silver print, $26.7 \times 40.5 \mathrm{~cm}$, Museum of Modern Art, New York, USA. (C) The Estate of Garry Winogrand, courtesy Fraenkel Gallery, San Francisco.

13 In 1977, this decision to evoke Boorstin was especially loaded given that, after writing The Image, the historian had gone on to condemn the campus protests and affirmative action of the 1960s. 
The image of the violent protestor is, of course, one of the most infamous strategies for depicting demonstrations as unstable mobs on the brink of anarchy. Widely used to this day, this trope was also common within coverage of the American antiwar movement. For example, as Melvin Small demonstrates, on 22 October 1969, after the 'Siege of the Pentagon' The Washington Post published an image of protestors confronting police on the Pentagon steps with the caption: 'compact mass of armed policemen resist a surging band of demonstrators', downplaying the police violence and peaceful rally which had occurred earlier in the day (Small 1994). In Winogrand's work, however, the only images of this kind are those of the hard-hat rallies. In New York City, for example, the crowd rises up behind a central figure whose crazed expression and stance seem to prefigure a more collective turn to violence (Figure 1). Here, Winogrand behaved just like the reporters who can be seen rushing to capture this outburst, photographing the central figure so that he almost appears to be swinging an American flag at the crowd. The work also includes a more sober record of the real violence which such groups, the police and the army committed against the antiwar movement. These include images of students fleeing a tear gas attack at Kent State and a gruesome shot of a young protestor with blood pouring down his face from a head wound. Winogrand was not always willing to attack or name the perpetrators of this violence. His images of the police, for example, are hardly a serious indictment-despite poking fun at their joyless attitude and sentimental patriotism. Yet his work gives a strong sense that it was predominantly pro-war groups or law enforcement which engaged in 'collective hysteria'.

Images of crowds shot from above are also a common feature of the press coverage of demonstrations. These images may be used to highlight the scale of a rally. However, they have also been used to downplay the diversity of the crowd, reducing it to a mechanical mass. ${ }^{14}$ Winogrand was clearly uncomfortable with this type of imagery as well. It makes a partial appearance in Peace Demonstration, Central Park, New York but mixed with a kind of post-apocalyptic atmosphere (Figure 3). Indeed, even here, Winogrand sought to impart a sense of movement to an otherwise static scene by shooting at a moment in which the entire crowd turned to watch a mass release of balloons. As previously suggested, this discomfort towards large politicised crowds made Winogrand fairly ignorant as to the political value of sit-ins and rallies; he later admitted that the speeches and songs bored him (Diamonstein and Winogrand 1982, parag. 32-34 of 215). However, it did lead him to foreground the range of political groups sometimes referred to as the new social movements. Just as figures on the New Left were attempting to rethink the traditional centrality of blue-collar workers, Winogrand was depicting not just labour unions, but gay liberation groups, the women's movement, the 'youth' and so on. This is not to say that these images are free from the mocking humour or even misogyny of his earlier street photographs. By focusing upon the variety of these groups, Winogrand may even have been trying to create a sense of chaos akin to that of the average Manhattan street. However, the resulting interplay between diversity and simultaneity provides a more effective foundation for approaching the, still prescient, problem of forming alliances between such groups than the sense of false unification often suggested in photographs of large politicised crowds. At the very least, Winogrand's project showed the crowd's complexity rather than conflating left and right.

\section{Conclusions}

In conclusion, while Winogrand's work may have been formalist through and through, this did not stop him from producing a rich document of protest culture of significant interest to the left. Indeed, if anything Winogrand pushed certain formalist motifs to such an extreme that they became de-anchored from their theoretical context and entered into an unlikely identity with protest. Winogrand was celebrated for his indifference to the subject matter of his photographs. But he pushed this in a new direction when he photographed the infrastructure of the art establishment, started

14 For a discussion of this see (Memou 2013, p. 23). 
shooting in an automatic stream and incorporated his photography into the process of everyday life. He was also seen as a figure who had understood and transcended photojournalism. Yet in doing so he also avoided both the media cynicism which surrounded the formalist project and the derogatory representations of protest produced by the mainstream media. As a result, he adopted a novel hybrid position between the moving spectacle of the politicised crowd and the structure of its surrounding media apparatus. To make this argument is not to celebrate Winogrand's 'genius' or project a clear leftist intention onto his work. Rather, Winogrand's achievement was to follow the logic of protest just far enough to expand the parameters of street photography in ways which allowed something new to emerge.

Unfortunately, this fragile rupture would prove short-lived. By the time Public Relations was exhibited in 1977, Winogrand had distanced himself from the political elements of the project and returned to his old methods and apolitical themes. His final finished work, Stock Photographs, adopted a significantly less ambitious approach to the public event by addressing a livestock show, rodeo and its participants. The project was something of a retread of previous works such as The Animals and Public Relations. Furthermore, those who posthumously explored his unprinted shots found them to be characterised by a diluted form of classical street photography and an increasingly bleak outlook. In this sense, the subversive potentialities of Winogrand's processual method gave way to a kind of bad infinity or stifling lassitude. This late sense of indirection has been attributed to a number of factors, not least his deteriorating health. However, it is hard not to feel that Winogrand was at his peak treading a fine line between street photography, protest, (pseudo) institutional critique and photojournalism, which was increasingly difficult to sustain. Indeed, as the political climate which underpinned Public Relations receded and the streets of western cities were increasingly given over to commerce and gentrification, street photography itself experienced something of a crisis. When asked in 2008 which figures had taken on the mantle of 1960s street photography, Tod Papageorge unwittingly epitomised its descent into a series of ever more inflated 'fictions' by naming only his former student Philip-Lorca Dicorcia (Papageorge and Schuman 2009, para. 53 of 67). Nevertheless, Joel Sternfeld's 2002 work Treading on Kings: Protesting the G8 in Genoa shows us that the productive tension between protest and classical street photography can still be reignited. Returning to Winogrand's Public Relations today reminds us that this tension was not external to photographic formalism but a contradiction at the heart of its core project.

Funding: This research received no external funding.

Acknowledgments: A version of this paper was first presented at EBAAS 2018, the 32nd European Association for American Studies and 63rd British Association for American Studies Conference, at King's College London. I would like to thank Stephanie Schwartz for kindly sharing her archival research on John Szarkowski's Protest Photographs.

Conflicts of Interest: The author declares no conflicts of interest.

\section{References}

Badger, Gerry. 1988. I Don't Give a Rap about Gasoline Stations-The Winogrand Problem. Creative Camera. No. 12. Available online: http://www.gerrybadger.com/i-dont-give-a-rap-about-gasoline-stations-thewinogrand-problem/ (accessed on 2 January 2019).

Balaschak, Chris. 2012. Planet of the Apes: John Szarkowski, My Lai, and The Animals. Art Journal 71: 7-25. [CrossRef] Boorstin, Daniel. 1962. The Image: Or What Happened to the American Dream. New York: Atheneum.

Bryan-Wilson, Julia. 2009. Art Workers: Radical Practice in the Vietnam War Era. Berkeley: University of California Press. Diamonstein, Barbaralee, and Garry Winogrand. 1982. An Interview with Garry Winogrand (1981). In Visions and Images: American Photographers on Photography, Interviews with Photographers. Edited by Barbaralee Diamonstein. New York: Rizoli, Available online: http://www.americansuburbx.com/2008/10/ theory-interview-with-garry-winogrand.html (accessed on 12 December 2018).

Edwards, Steve. 2009. Commons and Crowds: Figuring Photography from Above and Below. Third Text 23: 447-64. [CrossRef] 
Greenberg, Clement. 1986. The Camera's Glass Eye: Review of an Exhibition of Edward Weston. In Clement Greenberg, Collected Essays and Criticism. Edited by John O'Brian. Chicago: University of Chicago Press, vol. 2. First published 1946.

Hacking, Juliet. 2018. Photography and the Art Market. London: Lund Humphries and Sotheby's Institute of Art. Karmel, Pepe. 1981. Garry Winogrand, Public Eye. Art in America 69: 39-41.

Kracauer, Siegfried. 1995. Photography. In The Mass Ornament: Weimar Essays. Cambridge: Harvard University Press, pp. 57-63. First published 1927.

Lifson, Ben. 1982. Garry Winogrand's American Comedy. Aperture 86: 32-39.

Lucaites, John, and Robert Hariman. 2007. Dissent and Emotional Management. In No Caption Needed: Iconic Photographs, Public Culture, and Liberal Democracy. Chicago and London: University of Chicago Press, pp. 137-70.

Memou, Antigoni. 2013. Photography and Social Movements: From the Globalisation of the Movement (1968) to the Movement against Globalisation (2001). Manchester and New York: Manchester University Press.

Papageorge, Tod. 1977. Introduction. In Public Relations. New York: Museum of Modern Art, pp. 6-17.

Papageorge, Tod. 2008. Passing through Eden: Photographs of Central Park. Göttingen: Steidl.

Papageorge, Tod, and Aaron Schuman. 2009. "Park Life": An Interview with Tod Papageorge. Seesaw Magazine. p. 11. Available online: http://www.seesawmagazine.com/papageorgepages/papageorgeinterview.html (accessed on 15 January 2019). First published 2008.

Phillips, Christopher. 1982. The Judgement Seat of Photography. October 22: 27-63. [CrossRef]

Ribalta, Jorge. 2015. Introduction: Outline for a Map of the Debates around Documentary in the "Long 1970s". In Not Yet: On the Reinvention of Documentary and the Critique of Modernism. Madrid: Museo Nacional Centro de Arte Reina Sofía, pp. 19-45. First published 1981.

Rosler, Martha. 1992. In, Around and Afterthoughts (on Documentary Photography). In The Contest of Meaning: Critical Histories of Photography. Edited by Richard Bolton. Cambridge and London: The MIT Press, pp. 303-40.

Rubinfien, Leo. 2013. Garry Winogrand's Republic. In Garry Winogrand. Edited by Leo Rubinfien. San Francisco: San Francisco Museum of Modern Art in association with Yale University Press, pp. 12-61.

Small, Melvin. 1994. Covering Dissent: The Media and the Anti-Vietnam War Movement. New Brunswick: Rutgers University Press.

Soutter, Lucy. 1999. The Photographic Idea: Reconsidering Conceptual Photography. Afterimage 26: 8-10.

Szarkowski, John. 1966. The Photographer's Eye. New York: The Museum of Modern Art.

Szarkowski, John. 1970. Untitled (Memo. to Ricky Troiano), 20 May 1970. New York: The Museum of Modern Art Archives.

Szarkowski, John. 1988. Garry Winogrand: Figments from the Real World. New York: Museum of Modern Art.

Szarkowski, John. 2017. New Documents: Wall Label. In Arbus, Winogrand, Friedlander: New Documents, 1967. Edited by Sarah Hermanson Meister. New York: Museum of Modern Art. First published 1967.

Watson, April M. 2016. Picturing “Pseudo-Events" in Garry Winogrand's Public Relations. Exposure 49: 4-13.

Westerbeck, Collin, and Joel Meyerowitz. 2001. Still Going'. In Bystander: A History of Street Photography. Boston, New York and London: Bullfinch Press, pp. 373-92.

(C) 2019 by the author. Licensee MDPI, Basel, Switzerland. This article is an open access article distributed under the terms and conditions of the Creative Commons Attribution (CC BY) license (http://creativecommons.org/licenses/by/4.0/). 